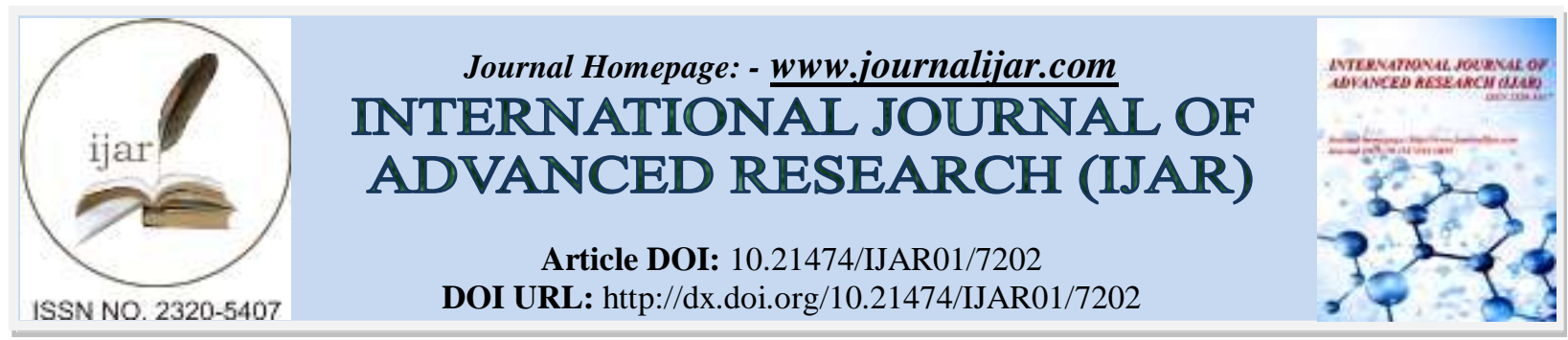

RESEARCH ARTICLE

\title{
INCISAL EDGE REPAIR AND DIASTEMA CLOSURE BY LIGHT CURE COMPOSITE RESIN BY USING 'PUTTY INDEX' A CASE SERIES.
}

\section{Dr. Raghunath Shil ${ }^{1}$, Dr. Debarpan Mandal $^{1}$, Dr. Abiskrita Das ${ }^{2}$, Dr. Indrajit Biswas ${ }^{2}$ and Dr. (Prof) U. K.} Das. $^{3}$.

1. Post Graduate Trainee, Department of Conservative Dentistry \& Endodontics, Guru Nanak Institute of Dental sciences \& Research, Panihati, Kolkata-114, West Bengal, India.

2. Post Graduate Trainee, Department of Conservative Dentistry \& Endodontics, Guru Nanak Institute of Dental sciences \& Research, Panihati, Kolkata-114, West Bengal, India.

3. Adjunct Professor, Department of Conservative Dentistry \& Endodontics, Guru Nanak Institute of Dental sciences \& Research, Panihati, Kolkata-114, West Bengal, India.

\section{Manuscript Info}

Manuscript History

Received: 04 April 2018

Final Accepted: 06 May 2018

Published: June 2018

Keywords:-

Composite resin bonding, speedy mock up, smile design.

\begin{abstract}
Increasing demand of smile design and improved esthetics is now well known in dental world. But the present lifestyle of everyone and of patients also, is busy, demanding, stressful, \& overwhelming at times. Composite is a material which can be molded, and is of same colour as that of teeth. They are reversible fix for teeth, but can be left in the mouth for several weeks or months. While the composite mock-ups are in the mouth, the dentist can make adjustments to them as per patient's choice. However, in smile design cases, the challenge is to meet patient's demands and esthetic expectations simultaneously keeping in mind another important factor i.e. time. Composite mock up provides reversible \&fast outcomes. This case report presents a case where the easy, fast composite mock up technique is used to provide a pleasing smile to patient within a matter of hours.
\end{abstract}

Copy Right, IJAR, 2018,. All rights reserved.

\section{Introduction:-}

Re-establishing a patient's lost natural dental esthetics is among the important topics of today's dentistry, in addition to function and phonation [1]. Colour, shape, and structural and position abnormalities of anterior teeth might lead to important esthetic problems for patients. If the crown of anterior tooth is fractured, it can be treated in a variety of ways such as fragment re-attachment, build-up using composite resin, laminate veneers and full crown [2].

Increased patient demand for optimal aesthetics with less invasive procedures has resulted in the extensive utilization of free hand composite resin bonding in the anterior region [3]. Composite is a material which can be molded, and is of same colour as that of teeth. They are reversible fix for teeth, but can be left in the mouth for several weeks or months. While the composite mock-ups are in the mouth, the dentist can make adjustments to them as per patient's choice $[4,5]$.

However, in smile design cases, the challenge is to meet patient's demands and esthetic expectations simultaneously keeping in mind another important factor i.e. time. Composite mock up provides reversible \& fast outcomes [6]. 
Using an intraoral mock up and a custom matrix allows practitioners to demonstrate their vision for the new smile $[7]$.

\section{CASE REPORT:}

\section{Case 1:}

A 22-year-old female patient reported to the department of Conservative Dentistry and Endodontics, with a chief complaint of spacing in her upper front teeth region. Patient's medical history was non-contributory and intraoral examination using a Vernier Caliper revealed interdental spacing between maxillary central incisors (1.5mm). No dental caries were observed upon both clinical and radiographic examinations.

Before starting the treatment, shade selection was done using the VITAPAN Classical Shade guide (A2). Then putty impression was taken and the putty index was tried in the patient's mouth. Isolation of the operating area was achieved with cotton rolls.

The midline diastema was closed by building up the mesial surfaces of central incisors one by one. It was decided to restore 21 first. No tooth preparation is necessary prior to adhesive procedures. Roughening of the enamel is recommended only when self-etch adhesives are to be used.

$37 \%$ phosphoric acid was applied on the mesial surface for 15 seconds, rinsed for 20 seconds, and slightly air-dried. Then, two coats of a single bottle bonding agent were applied using applicator tips and polymerized for 20 seconds with an LED light. Following this, a small increment of nano hybrid composite was placed near the "future" contact area and manually contoured over the mesial surface using Mylar strips. The increment was cured with LED light for 40 seconds, both from labial and palatal aspects. The same procedure was repeated for 11.

Once the diastema closure was accomplished finishing and polishing were done with Sof-Lex discs.

Once all the restorations were placed, the occlusion was verified in both centric and eccentric relations using an articulating paper. The patient was motivated for oral hygiene and informed for recalls.

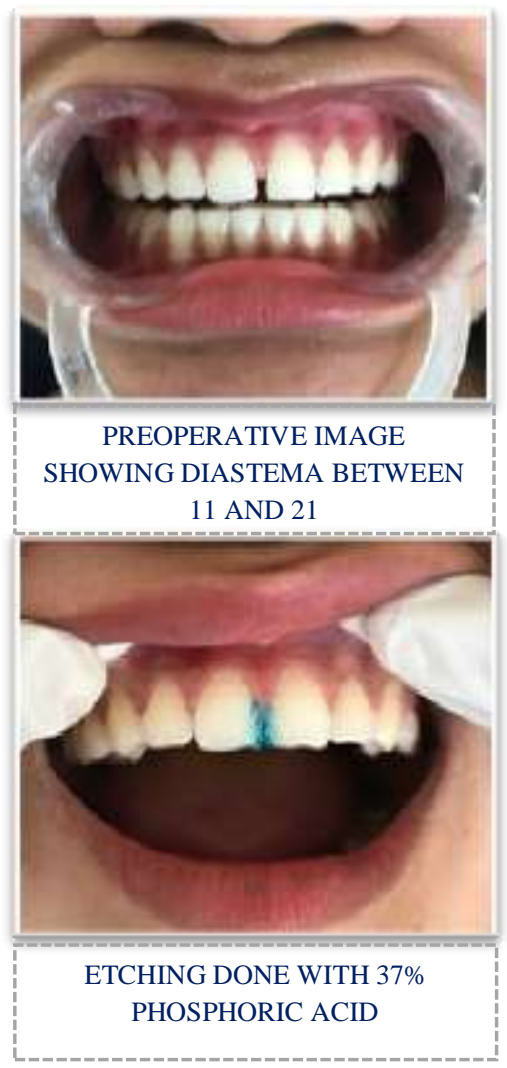

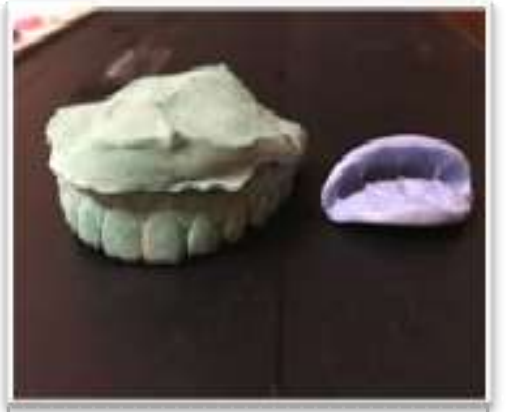

LIGHT CURE COMPOSITE RESIN BUILD UP ON CAST

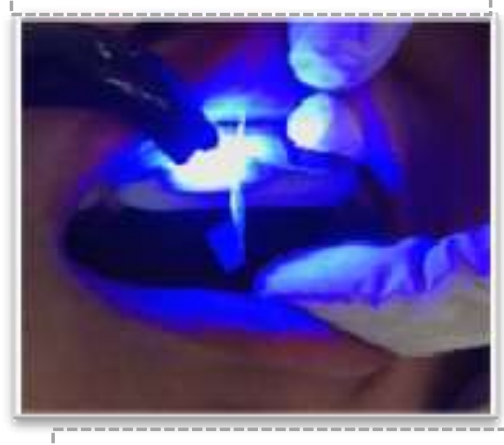

COMPOSITE RESIN BUILD UP AND LIGHT CURING

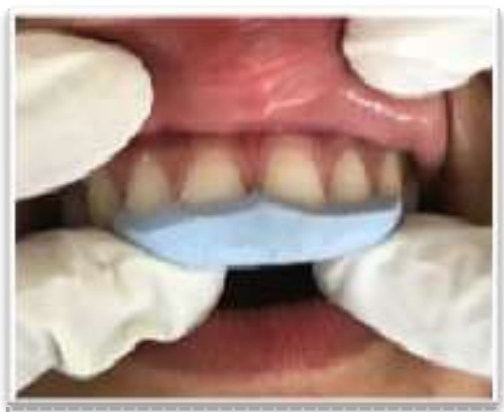

HEAVY BODY ELASTOMERIC IMPRESSION OF THE CAST

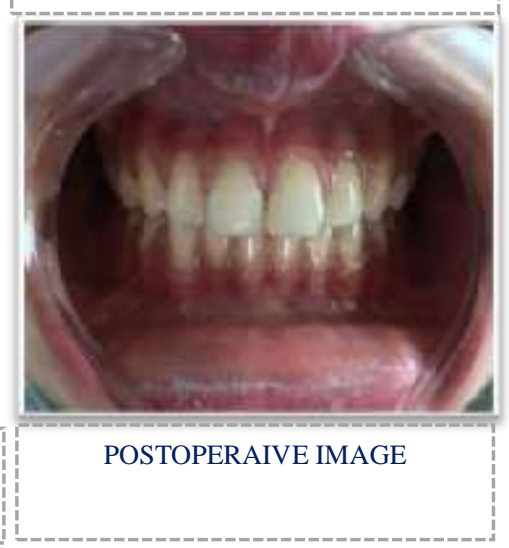




\section{Case 2:}

A 25 years old male patient reported to the department having a chief complain of broken upper front tooth and spacing between two front teeth.

Dental history revealed that he met with an accident 2 weeks back resulting in an injury.

Extraoral examination revealed no significant findings. Facial profile was bilaterally symmetrical without any proclination. During the intra-oral examination, a class II Ellis fracture of right maxillary central incisor was observed. Meanwhile, a small space was present in between two maxillary central incisors which were not appreciable during speech or smiling. The widest interdental space was between two central incisors approximately $1 \mathrm{~mm}$ in size. Overjet and overbite were found to be normal. To fully evaluate the case a visual assessment was performed and the patient's occlusion was analysed. Patient had good periodontal health and a stable intercuspal position, normal vertical and horizontal overlap, and canine-protected guidance and mucosal frenum attachment. Tooth 21 was not sensitive to percussion. On electrical and thermal pulp testing maxillary central incisors showed normal vitality response.

Intraoral periapical radiograph clearly shows enamel and dentin fracture without involvement of pulp in the tooth 21 and there was no widening of PDL space and no periapical radiolucency was present. Final diagnosis of Elis class II fracture of 11 with Diastema present between 11 and 21. Direct composite resin restoration using putty index technique was planned that will be providing near accurate esthetic and visualization on the part of patient as how his new smile will look like.

Diagnostic impressions of both the arches were made and light cured composite resin mock-up was done and shown to the patient. A silicone putty index was made which was thick enough to allow for rigidity. Using \#11 blade, the putty index was cut into two halves, palatal and buccal and tried the palatal half of the index in the patient's mouth and verified seating.

Before starting the treatment, oral prophylaxis and shade selection was done using the Vitapan Classical Shade guide (A2).

Isolation was done using cotton rolls. The required beveling the fractured portion of teeth was done. 37\% phosphoric acid was applied on the mesial surface for 15 seconds and rinsed for 20 seconds. Then, two coats of a single bottle bonding agent were applied using applicator tips and polymerized for 20 seconds with an LED light. Care was taken to apply uniform coats of the bonding agent especially near the gingival area. Following this, a small increment of composite resin was placed on the future contact area of the putty index and seated swiftly in the patient's mouth. Light curing was done for 40 seconds with putty index in place and after removing the putty index, cured again for next 40 seconds.

The midline diastema was closed by building up the mesial surfaces of central incisors one by one. A mylar strip was placed in between 11 and 21 to act as a frame against which to pack composite and small increment of composite was added to 11 . Each increment was cured for 40 seconds from both labial and palatal aspects. The same procedure was repeated for 21. Final finishing and polishing were accomplished with Sof-Lex discs.

Once all the restorations were placed, the occlusion was verified in both centric and eccentric relations using an articulating paper.

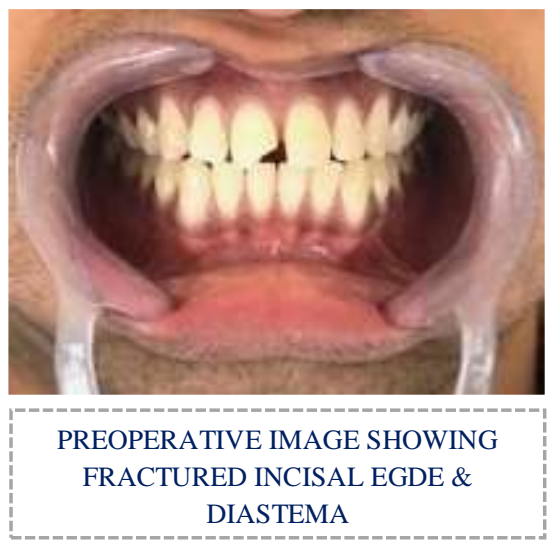

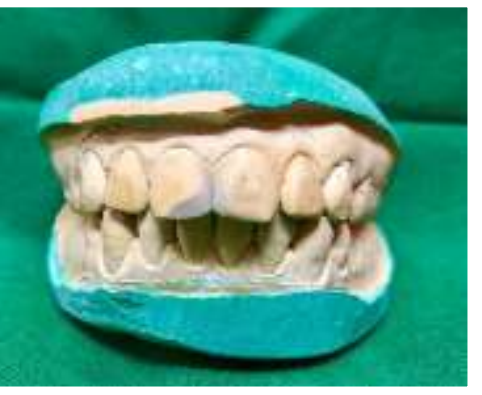

LIGHT CURE COMPOSITE RESIN BUILD UP ON CAST

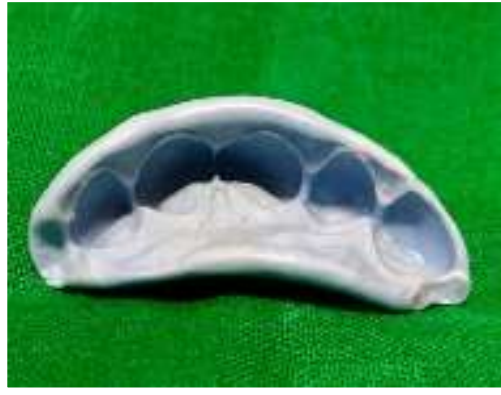

HEAVY BODY ELASTOMERIC IMPRESSION OF THE CAST 


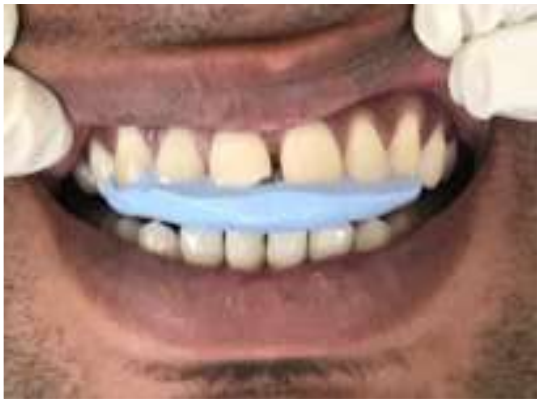

FITTING OF IMPRESSION IN

PATIENTS MOUTH

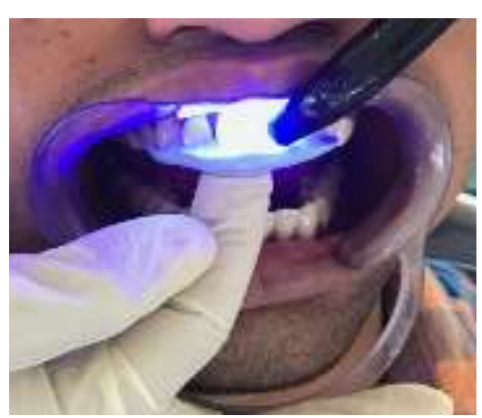

COMPOSITE RESIN BUILD UP AND LIGHT CURING

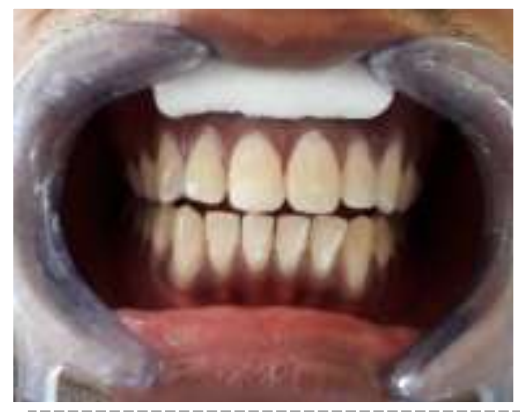

POSTOPERAIVE IMAGE

\section{Case 3:}

A 21 years old male patient reported to the department having a chief complain of broken upper front tooth region. Dental history revealed that he met with an accident 5 years back resulting in an injury. Medical history was not significant.

Extraoral examination: Facial profile was bilaterally symmetrical without any proclination. Intra-oral examination: Class II Ellis fracture of right maxillary central incisor was observed. Patient had good periodontal health and a stable intercuspal position. Tooth 11 was not sensitive to percussion.

On electrical and thermal pulp testing maxillary central incisors showed normal vitality response.

Intraoral periapical radiograph clearly shows enamel and dentin fracture without involvement of pulp in the tooth 11 and there was no widening of PDL space and no periapical radiolucency was present. Final diagnosis of Elis class II fracture of 11. Direct composite resin restoration using putty index technique was planned.

Diagnostic impressions of both the arches were made and light cured composite resin mock-up was done. A silicone putty index was made which was thick enough to allow for rigidity. Using \#11 blade, the putty index was cut into two halves, palatal Isolation was done using cotton rolls.

Before starting the treatment, oral prophylaxis and shade selection was done using the Vitapan Classical Shade guide (A3). The required beveling the fractured portion of teeth was done.

$37 \%$ phosphoric acid was applied on the mesial surface for 15 seconds and rinsed for 20 seconds. Then, two coats of a single bottle bonding agent were applied using applicator tips and polymerized for 20 seconds with an LED light. Following this, a small increment of composite resin was placed on the future contact area of the putty index and seated swiftly in the patient's mouth. Light curing was done for 40 seconds with putty index in place and after removing the putty index, cured again for next 40 seconds.

Once all the restorations were placed, the occlusion was verified in both centric and eccentric relations using an articulating paper. After completing the procedure Oral hygiene instructions were given. And patient was recalled after 1 week and 6 months for follow up. 

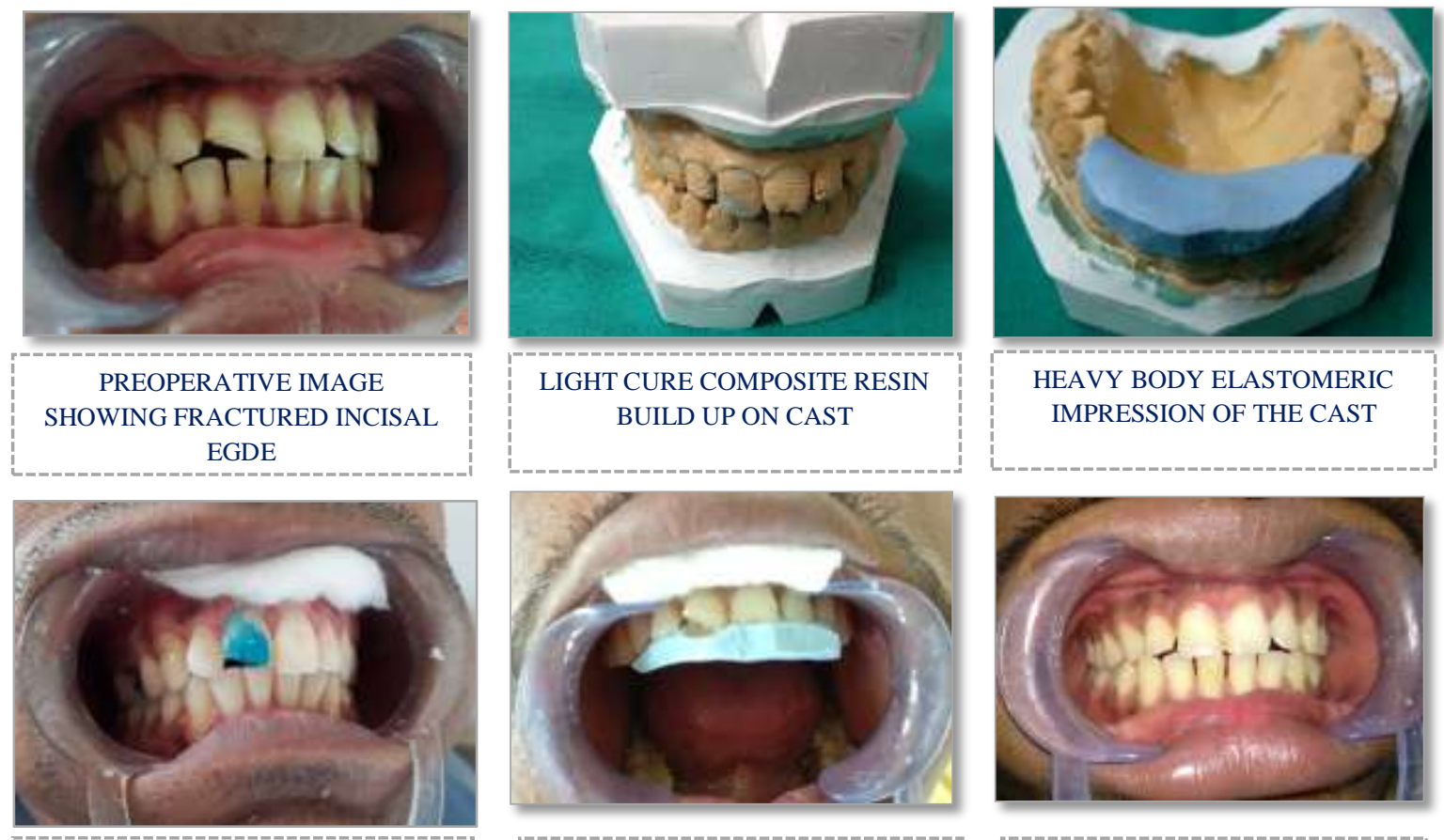

LIGHT CURE COMPOSITE RESIN BUILD UP ON CAST
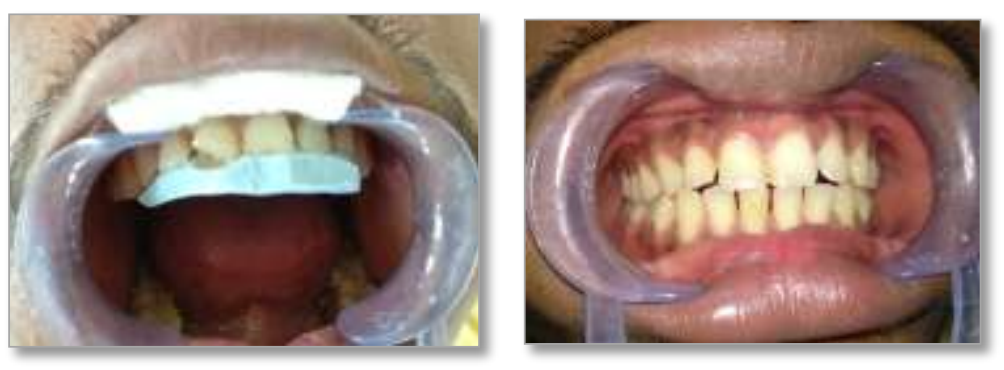

ETCHING DONE WITH 37\% PHOSPHORIC ACID

FITTING OF IMPRESSION IN PATIENTS MOUTH

POSTOPERAIVE IMAGE

\section{Case 4:}

A 32 years old male patient reported to the department having a chief complain of unpleasing smile due to presence of broken upper front tooth.

During the intra-oral examination, a class II Ellis fracture of left maxillary central incisor was diagnosed. To fully evaluate the case a visual assessment was performed and the patient's occlusion was analysed. On electrical and thermal pulp testing all maxillary incisors showed normal vitality response.

Intraoral periapical radiograph clearly shows enamel and dentin fracture without involvement of pulp in the tooth 21 and 22. Final diagnosis of Elis class II fracture of 21 and 22. Composite resin restoration using pre-restoration index technique was planned for Tooth 21 and 22.

Putty impression was taken. Light cured composite resin mock-up was done and putty index was made duplicating the restoration. It was made to assist in guiding the application of the first palatal composite layer. On his first visit day, shades of tooth was evaluated using the VITAPAN shade guide for resin selection. The putty index was tried in the patient's mouth. Isolation of the operating area was achieved with cotton rolls.

The preparation was etched -with $37 \%$ phosphoric acid for 30 seconds, rinsed with water and dried. A single layer of bonding agent (Tetric $\mathrm{N}$ Bond, Ivoclair Vivadent) was applied according the manufacturer direction and cured for 20 seconds with the LED composite curing unit. A thin layer of nanohybrid composite (Tetric N Ceram, Ivoclair Vivadent) was incrementally applied to the tooth surface and light cured for 40 seconds. Finally shaping was done with 12 fluted carbide bur on the facial surfaces, excess was removed and contouring at the gingival and labial margin performed. Finishing, contouring and polishing were done with a super snap mini kit (Shofu) and composite polishing paste. 

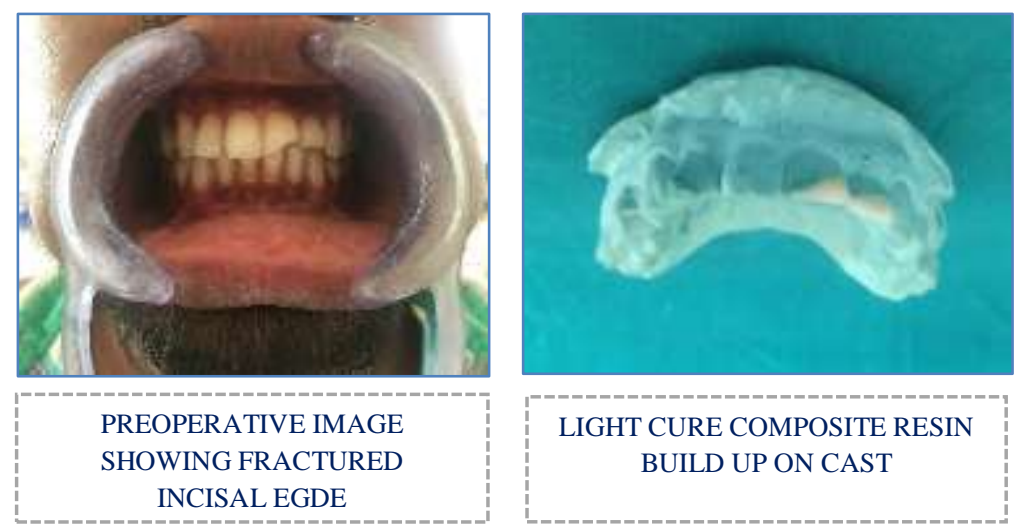

\section{LIGHT CURE COMPOSITE RESIN} BUILD UP ON CAST

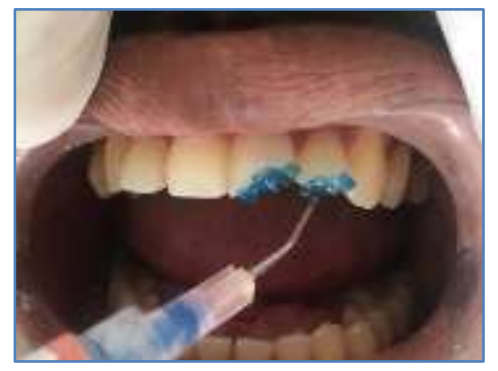

ETCHING DONE WITH 37\% PHOSPHORIC ACID

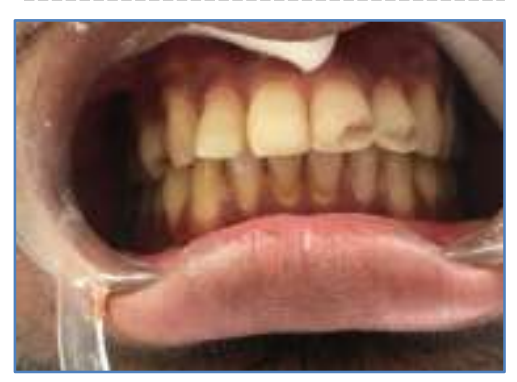

FITTING OF IMPRESSION IN PATIENTS MOUTH

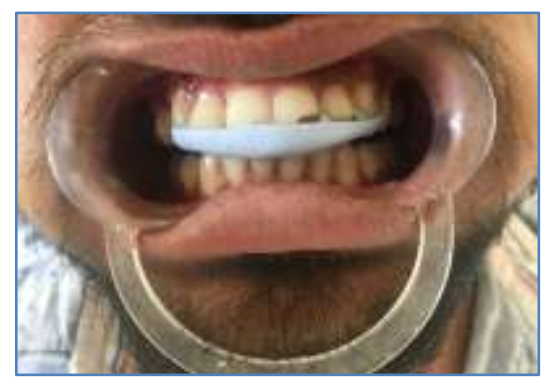

HEAVY BODY ELASTOMERIC IMPRESSION OF THE CAST

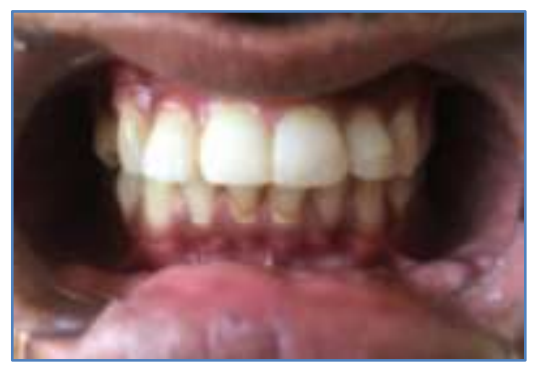

POSTOPERAIVE IMAGE

\section{Discussion:-}

The coronal fracture is an unexpected occurrence and requires professional preparation. A coronal fracture involving non-complicated enamel and dentin might receive different kinds of treatment such as restoration with composite materials or re-attachment of fragments with or without additional retention [8]. The choice of resin composite should be focused on aspects related to the strength and aesthetics. According Nahsan et al. young teeth show a naturally high value and thus require resins with such characteristics; in consequence, the reproduction of enamel should be done with composite resins that presents transparent characteristics [9].

The intraoral composite mock-up which serves as a matrix for fast speedy work, is primarily used for indirect restorative cases in the aesthetic zone [10].

Though it is extremely useful in a variety of applications eg. Smile design, Class IV fractures, and direct veneers. But if only the addition of tooth structure is needed to enhance the smile, as in a diastema closure or the repair of a fractured tooth, this process is almost reversible, conservative and relatively inexpensive means of enhancing one's smile4 and is often carried out in a single visit procedure in many dental practices [11,12].

Resin stratification initiating from the palatal enamel is the best choice, particularly in fractured anterior teeth, with a transparent composite to create the underlying structure for the subsequent layers [13]. The palatal enamel can be constructed with the use of a personalized guide like Silicone Matrix [14].

If any adjustments need to be made, then the composite can be re-modeled and the new effect evaluated now or later. Should the patient decide not to go ahead with further treatment, the composite mock-ups can be removed and the original teeth polished up to their original state. It can be applied as a thin veneer over study models or directly onto natural teeth. This process can be repeated several times until a result is achieved that both the patient and the Dentist are pleased with 15]. 


\section{Conclusion:-}

Restoring a fractured tooth being a complex procedure, a simple yet effective technique is always desired that will fulfil all the requirements of dental personnels. Restorative procedures should be planned and executed with attention to dental contours and convexities, facilitating the re-establishment of function and aesthetics

\section{References:-}

1. Elias AC, Sheiham A. The relationship between satisfaction with mouth and number and position of teeth. J Oral Rehabil 1998;25(9):649-661.

2. Peumans M, Van Meerbeek B, Lambrechts P, Vanherle G. Porcelain veneers: a review of the literature. J Dent 2000;28(3):163-77.

3. Van Meerbeek B, Vanherle G, Lambrechts P, Braem M. Dentin- and enamel- bonding agents. Curr Opin Dent 1992;2:117-27.

4. Magne P, Hanna J, Magne M. The case for moderate, "guided prep" indirect porcelain veneers in the anterior dentition. The pendulum of porcelain veneer preparations: from almost no-prep to over-prep to no-prep. Eur J Esthet Dent 2013;8(3):376-88.

5. Layton DM, Walton TR. The up to 21-year clinical outcome and survival of feldspathic porcelain veneers: accounting for clustering. Int J Prosthodont 2012;25(6):604-612.

6. Layton DM, Clarke M, Walton TR. A systematic review and meta-analysis of the survival of feldspathic porcelain veneers over 5 and 10 years. Int J Prosthodont 2012;25(6):590-603.

7. Peumans M, De Munck J, Fieuws S, Lambrechts P, Vanherle G, Van Meerbeek B. A prospective ten-year clinicaltrial of porcelain veneers. J Adhes Dent 2004;6(1):65-76.

8. Ozturk E, Bolay S, Hickel R, Ilie N. Shear bond strength of porcelain laminate veneers to enamel, dentine and enamel-dentine complex bonded with different adhesive luting systems. J Dent 2013;41(2):97-105

9. Marshall SJ, Bayne SC, Baier R, Tomsia AP, Marshall GW. A review of adhesion science. Dent Mater 2010;26(2):e11-e16.

10. Mangani F, Cerutti A, Putignano R, Bollero R Madini L. Clinical approach to anterior adhesive restorations using resin composite veneers. Eur J Esthet Dent 2007;2(2):188-209.

11. Korkut B, Yanıkoğlu F, Günday M. Direct composite laminate veneers: Three case reports. J Dent Res Dent Clin Dent Prospects. 2013;7(2):105-111.

12. Zorba YO, Bayindir YZ, Barutcugil C. Direct laminate veneers with resin composites: two case reports with five-year follow-ups. J Contemp Dent Pract 2010;11(4):E056-E062.

13. Mangani F, Cerutti A, Putignano A, Bollero R, Madini L. Clinical approach to anterior adhesive restorations using resin composite veneers. Eur J Esthet Dent 2007;2(2):188-209.

14. Horvath S, Schulz CP. Minimally invasive restoration of a maxillary central incisor with a partial veneer. Eur J Esthet Dent 2012;7(1):6-16.

15. Tam LE, McComb D. Shear bond strengths of resin luting cements to laboratory made composite resin veneers. J Prosthet Dent 1991;66(3):314-21. 